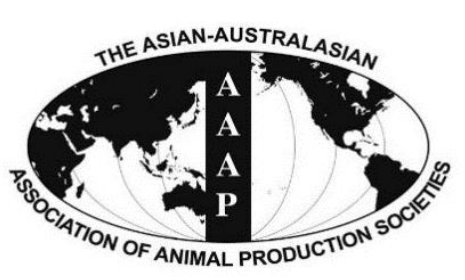

Open Access

Asian Australas. J. Anim. Sci.

Vol. 29, No. 8 : 1083-1094 August 2016

http://dx.doi.org/10.5713/ajas.15.0696

www.ajas.info

pISSN 1011-2367 elSSN 1976-5517

\title{
Genetic Parameter Estimates of Carcass Traits under National Scale Breeding Scheme for Beef Cattle
}

\author{
ChangHee Do, ByungHo Park ${ }^{1}$, SiDong Kim ${ }^{1}$, TaeJung Choi ${ }^{1}$, BohSuk Yang ${ }^{1}$, \\ SuBong Park ${ }^{\mathbf{1}}$, and HyungJun Song* \\ Division of Animal and Dairy Science, Chungnam National University, Daejeon 34134, Korea
}

\begin{abstract}
Carcass and price traits of 72,969 Hanwoo cows, bulls and steers aged 16 to 80 months at slaughter collected from 2002 to 2013 at 75 beef packing plants in Korea were analyzed to determine heritability, correlation and breeding value using the Multi-Trait restricted maximum likelihood (REML) animal model procedure. The traits included carcass measurements, scores and grades at $24 \mathrm{~h}$ postmortem and bid prices at auction. Relatively high heritability was found for maturity $(0.41 \pm 0.031)$, while moderate heritability estimates were obtained for backfat thickness (0.20 \pm 0.018$)$, longissimus muscle (LM) area $(0.23 \pm 0.020)$, carcass weight $(0.28 \pm 0.019)$, yield index $(0.20 \pm 0.018)$, yield grade $(0.16 \pm 0.017)$, marbling $(0.28 \pm 0.021)$, texture $(0.14 \pm 0.016)$, quality grade $(0.26 \pm 0.016)$ and price $/ \mathrm{kg}(0.24 \pm 0.025)$. Relatively low heritability estimates were observed for meat color $(0.06 \pm 0.013)$ and fat color $(0.06 \pm 0.012)$. Heritability estimates for most traits were lower than those in the literature. Genetic correlations of carcass measurements with characteristic scores or quality grade of carcass ranged from -0.27 to +0.21 . Genetic correlations of yield grade with backfat thickness, LM area and carcass weight were $0.91,-0.43$, and -0.09 , respectively. Genetic correlations of quality grade with scores of marbling, meat color, fat color and texture were $-0.99,0.48,0.47$, and 0.98 , respectively. Genetic correlations of price $/ \mathrm{kg}$ with LM area, carcass weight, marbling, meat color, texture and maturity were $0.57,0.64,0.76,-0.41,-0.79$, and -0.42 , respectively. Genetic correlations of carcass price with LM area, carcass weight, marbling and texture were $0.61,0.57,0.64$, and -0.73 , respectively, with standard errors ranging from \pm 0.047 to \pm 0.058 . The mean carcass weight breeding values increased by more than $8 \mathrm{~kg}$, whereas the mean marbling scores decreased by approximately 0.2 from 2000 through 2009 . Overall, the results suggest that genetic improvement of productivity and carcass quality could be obtained under the national scale breeding scheme of Korea for Hanwoo and that continuous efforts to improve the breeding scheme should be made to increase genetic progress. (Key Words: Hanwoo, Carcass, Genetic Parameters, Genetic Progress, National Breeding Scheme)
\end{abstract}

\section{INTRODUCTION}

Hanwoo (Bos taurus coreanae) was the only cattle breed on the Korean peninsula for over 5,000 years. After implementation of the beef grading system in Korea in 1995, significant differences in price appeared according to carcass quality grades, resulting in increased interest in Hanwoo carcass quality. Quality grades of Korea were designed to reflect differences in expected eating quality

\footnotetext{
* Corresponding Author: HyungJun Song. Tel: +82-42-821-8969, Fax: +82-42-823-2766, E-mail: kiya89@cnu.ac.kr

${ }^{1}$ National Institute of Animal Science, RDA, Cheonan 31000, Korea.
}

Submitted Aug. 24, 2015; Revised Nov. 23, 2015; Accepted Mar. 21, 2016 among carcasses. Beef characteristics are important factors that influence perceived eating quality, and the intramuscular fat quantity among those is known to be the strongest quality attribute in most countries (Hocquette et al., 2005). Evaluation of beef quality in Korea is based on the marbling score in conjunction with supplementary scores such as meat and fat color, maturity and texture. Records of carcass traits including carcass characteristic scores of Hanwoo have been collected nationwide in Korea since 1995 along with pedigree information. The selection for nationwide artificial insemination (AI) sires of Hanwoo may require implementation of a large scale breeding scheme for better quality and productivity of beef, such as progeny test (Park et al., 2013). The Guidelines of Uniform 
Beef Improvement Programs (BIF, 2010) have facilitated the use of records to improve beef productivity, and the National Beef Quality Audit (Moore et al., 2012) has provided industry guidelines for quality conformance in the US. Numerous studies have also been conducted to investigate the carcass traits of various cattle breeds and provide genetic characteristics of the breeds (Koots et al., 1994; Choy et al., 2005; Ríos-Utrera, 2005; Casas et al., 2010; Park et al., 2013; Koh et al., 2014). Studies on estimation of genetic parameters with few carcass traits (3 or 5 traits) were carried out for probing better estimation in Hanwoo (Lee, 2004; Roh et al., 2004). Hwang et al. (2008) also reported genetic parameters for 5 carcass traits of Hanwoo. Roh et al. (2010) estimated genetic parameters of carcass traits along with ultra scanning traits for selection of sires. Even though Hanwoo is the only breed used for beef production in Korea except for dairy cattle, some aspects of Hanwoo carcass characteristics have not been sufficiently and broadly revealed. Therefore this study associated with the Hanwoo cow performance test project in Korea provides information of regarding carcass including a series of carcass quantity, quality, price, grade and index traits as a total of 13 carcass traits. Further, estimates of genetic parameters for these carcass traits and genetic trends in Hanwoo cattle on a national scale are presented herein.

\section{MATERIALS AND METHODS}

\section{Data}

The carcass traits of 72,969 Hanwoo born from 2001 through 2011 (cows: 43,955, bulls: 5,849, steers: 23,165) at eight herd recording centers (so called Hanwoo Saupdan) were recorded at 75 beef packing plants from 2002 through 2013. The carcass traits, including grades, measurements and characteristic scores of animals aged 16 to 80 months at slaughter, were recorded by the official graders according to the Animal Products Grade Service (APGS) based on the APGS reference index. The pedigree data of animals were provided by the Korea Animal Improvement Association (KAIA) and the structure of pedigree information was shown by Park et al. (2013).

At slaughter all internal organs and heads were removed, as well as portions of the tail and legs. At $24 \mathrm{~h}$ postslaughter, the carcasses were weighed and evaluated by an official grader for back fat thickness and ribeye area. As shown in Figure 1, backfat thickness was evaluated in terms of thickness of fat over the longissimus muscle (LM) measured perpendicular to the outside surface at a point two thirds of the length of the rib eye from its chine bone end (Park et al., 2002). The area of the rib eye was determined at the surface using a grid at the same point.

Marbling score measured marbling in the rib eye area, while texture was based on the water folding capacity and

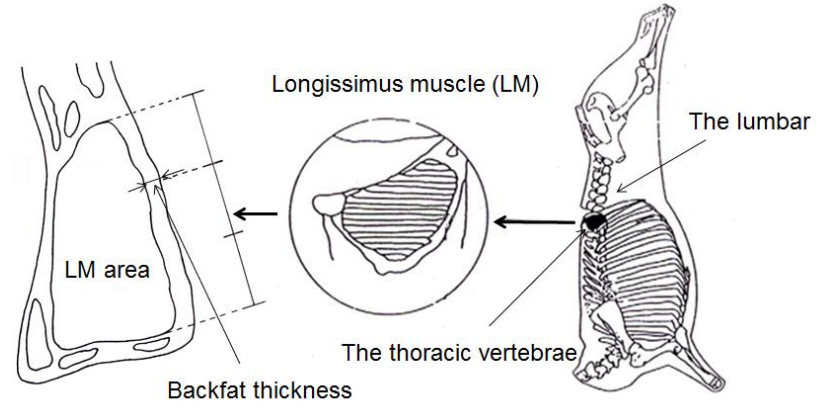

Figure 1. The locations at which backfat thickness and longissimus muscle (LM) area were measured (KIAPQE, 2012).

elasticity of the rib eye area in the grade decision region and maturity considered ossification of cartilage in the left semiconductor backbone thorn promontory. The scales of each score for carcass characteristics could be summarized as marbling ( $1=$ devoid and $9=$ abundant $)$, lean meat color $(1=$ brightly cherry red and $7=$ extremely dark red $)$, fat color $(1=$ white and $7=$ dark yellow $)$, texture $(1=$ proper exudate and good elasticity, and $3=$ very high or low exudate and poor elasticity) and maturity $(1=$ youthful and $9=$ mature).

The yield index (Park et al., 2002) represents the retail cut percent, which is predicted from three variables: carcass weight $(\mathrm{kg})$, ribeye area $\left(\mathrm{cm}^{2}\right)$, and back fat thickness $(\mathrm{mm})$. The correction factors of the variables were as follows: 0.625 for back fat thickness, 0.130 for ribeye area, and 0.024 for carcass weight. In the case of Hanwoo carcasses, a compensating factor of 3.23 was added to the function for yield index as follows:

$$
\begin{aligned}
\text { Yield index }= & 68.184-[0.625 \times \text { back fat thickness }(\mathrm{mm})] \\
& +\left[0.130 \times \text { ribeye area }\left(\mathrm{cm}^{2}\right)\right] \\
& -[0.024 \times \text { carcass weight }(\mathrm{kg})]+3.23
\end{aligned}
$$

The beef grading system of Korea reveals two types of information: quality grade and yield grade. Yield grades are primarily stratified by yield index, with $\mathrm{A}, \mathrm{B}$, and $\mathrm{C}$ indicating yield index $\geq 67.50,62.00 \leq$ yield index $<67.50$, and yield index $<62.00$, respectively. For quality grade, a provisional grade is given according to the degrees of marbling ( $1=$ devoid and $9=$ abundant). Marbling scores of 8 and 9,6 and 7, 4 and 5, 2 and 3, and 1 were roughly categorized as $1++, 1+, 1,2$, and 3 , respectively, in the quality grades. The lean meat color, fat color, texture, and maturity of carcass were also evaluated. The quality grade of carcass decreased from the provisional quality grade in the case of a pale and dark color of meat, dark yellow color of fat, very high or low exudate, poor elasticity, and high maturity. The grades for quality and yield were converted to scores of 1 to 6 (for $1++, 1+, 1,2,3$, and D) and 1 to 4 (for A, B, C, and D), respectively, for this study. Furthermore, 
the grades were treated as continuous quantitative variables similar to other carcass scores. The full descriptions of the 13 traits are summarized in Table 1. Data for both extremes $(0.5 \%)$ of each measured trait were removed prior to analysis.

\section{Statistical analysis}

Components of (co)variance, heritabilities, and genetic correlations for the carcass traits were estimated by the restricted maximum likelihood (REML) method with the Multi-Trait Animal model using the Wombat program (Meyer, 2013). The average information matrix was used to approximate sampling errors of (co)variance components, heritabilities, and genetic correlations (Meyer, 2013). The parameters were estimated repeatedly by models with seven or less carcass traits for easy computation until all genetic (co)variances for the 13 carcass traits were obtained.

Fixed effects considered in all models included sex (cow, bull, and steer), age of animal at slaughter (continuous variable: 16 to $80 \mathrm{mo}$ ), and birth year (12) within the herd recording center (8). For data originating from the herd recording centers as consulting service providers to farms, birth year within herd recording centers were defined as a contemporary group. The average number of heads slaughtered per year was 6.7 , and at least 50 herds were required to set up a herd recording center (Hanwoo Saupdan) according to the rules set by the government. Consequently, it was easy to secure proper numbers of observations in contemporary groups. To eliminate outliers from the data, all animals aged 16 mo or less were excluded, as were bulls and steers older than $36 \mathrm{mo}$, and cows aged above 80 mo.
Age at slaughter was considered a covariate in the mixed linear models of all traits. Fixed covariable age month was fitted to the ordinary quadratic regression without intercept (Meyer, 2013).

Many fluctuations in beef price have occurred in the Korean market in recent years owing to changes in feed price, disease, beef consumption, and import volume of beef. When price traits (carcass price $[\mathrm{CP}]$ and price $/ \mathrm{kg}$ ) were dependent variables, slaughter year $(n=12)$ was added as a fixed effect in the models so that changes in beef price in the market could be taken into account instead of standardization of price per animal (McHugh et al., 2011). Consideration of the effects of slaughter year on contemporary groups was not necessary since animals had different ages at slaughter (Figure 2).

It is common to obtain discrete and/or continuous responses from the observations of animals. Most of the quantitative attribute traits shown in Table 1 were continuous and the evaluated scores of carcass characteristics (including carcass grades) seemed to be categorical and have multinomial distributions. For efficiency of parameter estimation, Liang et al. (1992) proposed a multivariate extension of quasi-likelihood known as generalized estimating equations to estimate the regression coefficients without completely specifying the joint distribution of the multivariate responses, including categorical variable. We assumed that all traits had multivariate normal distribution. If $a$ represents the vector of animal genetic effects for the traits and $e$ represents the vector of residual effects, the random effects can be assumed to follow normal distributions with zero means

Table 1. Descriptions of the measurements, grades, and scores analyzed in the study

\begin{tabular}{|c|c|c|c|}
\hline Carcass traits & Description & Attribute & Unit, scale \\
\hline \multicolumn{4}{|l|}{ Quantitative attribute } \\
\hline Carcass weight & Cold carcass weight after $24 \mathrm{~h}$-chill period & Measurements & $\mathrm{kg}$ \\
\hline LM area & The left side of each carcass was cut between the last rib and the first & Measurements & $\mathrm{cm}^{2}$ \\
\hline Backfat thickness & lumbar vertebrae and measured for LM area and backfat thickness & Measurements & $\mathrm{mm}$ \\
\hline Yield index (retail cut \%) & $\begin{aligned}= & 68.184-[0.625 \times \text { backfat thickness }(\mathrm{mm})]+\left[0.130 \times \mathrm{LM} \text { area }\left(\mathrm{cm}^{2}\right)\right] \\
& -[0.024 \times \text { carcass weight }(\mathrm{kg})]+3.23\end{aligned}$ & $\begin{array}{l}\text { Predicted dressed } \\
\text { meat percentage }\end{array}$ & $\%$ \\
\hline Yield grade & A (good), B, C, D (poor) & Assigned grade & \\
\hline Carcass price & Bid price at carcass auction & Carcass value & 1,000 Won \\
\hline \multicolumn{4}{|l|}{ Qualitative attribute } \\
\hline Marbling & Devoid to abundant & Evaluated score & 1 to 9 \\
\hline Meat color & Bright cherry red to extremely dark red & Evaluated score & 1 to 7 \\
\hline Fat color & White to dark yellow & Evaluated score & 1 to 7 \\
\hline Texture & $\begin{array}{l}\text { Proper exudate to very high or low exudate, and good elasticity to } \\
\text { poor elasticity }\end{array}$ & Evaluated score & 1 to 3 \\
\hline Maturity & Youthful to mature & Evaluated score & 1 to 9 \\
\hline Quality grade & $1++($ excellent), $1+, 1,2,3, \mathrm{D}$ (poor) & Evaluated grade & \\
\hline Price $/ \mathrm{kg}$ & USD $1.00=$ Korean Won 1,100 & Carcass unit value & 1,000 Won \\
\hline
\end{tabular}

LM, longissimus muscle. 


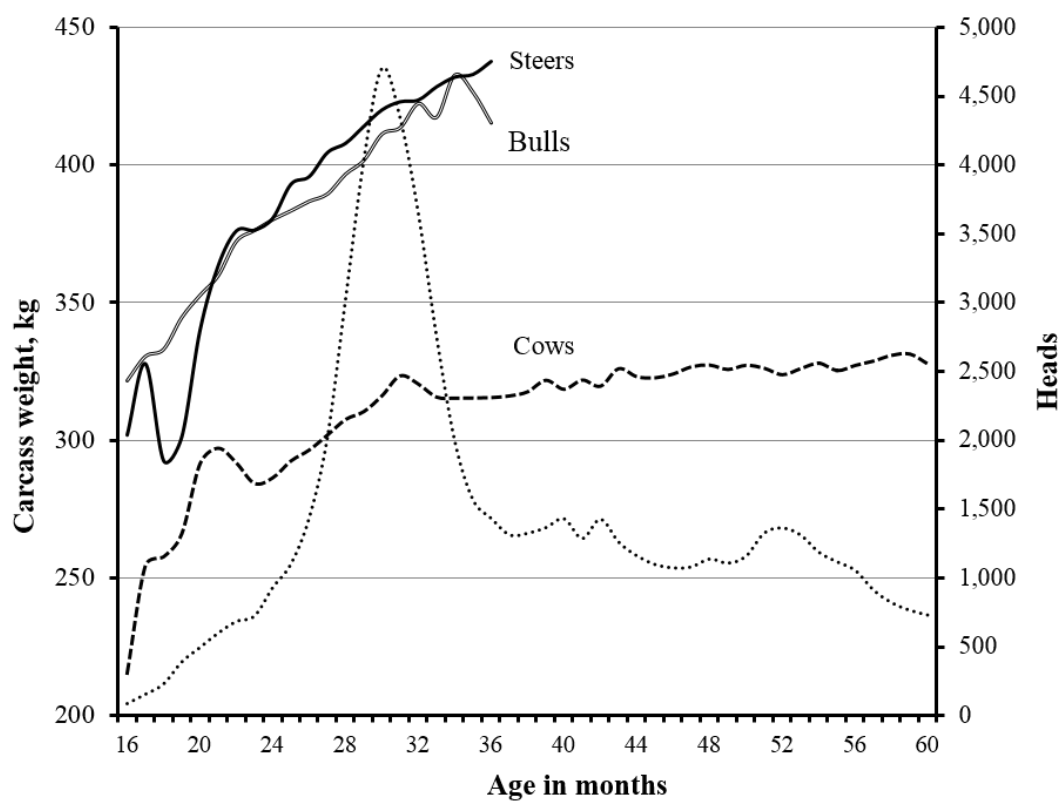

Figure 2. Least square means of carcass weight according to sex and frequency of age (dotted line).

and the following distribution parameters:

$$
\operatorname{var}\left[\begin{array}{l}
a \\
e
\end{array}\right]=\left[\begin{array}{cc}
A \otimes G & 0 \\
0 & I \otimes R
\end{array}\right]
$$

where, $A$ is the numerator relationship matrix; $G$ is a matrix with order 13 , the covariance matrix of the genetic effect between traits; I is the identity matrix of the appropriate dimension in each case, and $\mathrm{R}$ is the covariance matrix of residual effects between the traits. The residuals effects include all effects except additive genetic effects, such as dominance, maternal effects and environmental effects. The correlations of residual effects could be obtained from the covariances.

\section{RESULTS AND DISCUSSION}

\section{General description}

The statistics for all 14 observations based on individual carcasses are shown in Table 2. Lee et al. (2008) reported that means of carcass weight $(\mathrm{kg})$, back fat thickness $(\mathrm{mm})$, $\mathrm{LM}$ area $\left(\mathrm{cm}^{2}\right)$, yield index, marbling score, meat color, fat color, texture and maturity were $419.75 \pm 39.43,4.75 \pm 1.50$, $71.50 \pm 11.21,68.96 \pm 1.29,1.25 \pm 0.50,6.00 \pm 0.00,4.00 \pm 0.00$, $2.00 \pm 0.00$, and $4.00 \pm 0.82$, respectively, for Hanwoo bulls. Figure 2 shows the differences of carcass weight for cows, bulls and steers along with their ages. It could allow us to conjecture the growth of Hanwoo breed in these days. The carcass weights of Hereford, Angus, Brangus, Beefmaster,

Table 2. Descriptive statistics of carcass traits and price traits

\begin{tabular}{|c|c|c|c|c|c|}
\hline & No & Mean & SD & Minimum & Maximum \\
\hline Slaughter age (mo) & 72,969 & 41.1 & 14.3 & 16 & 80 \\
\hline Backfat thickness (mm) & 50,758 & 11.2 & 5.0 & 2 & 31 \\
\hline $\mathrm{LM}$ area $\left(\mathrm{cm}^{2}\right)$ & 50,758 & 81.8 & 11.5 & 32 & 117 \\
\hline Carcass weight (kg) & 72,969 & 357.1 & 61.8 & 168 & 528 \\
\hline Yield index & 50,120 & 66.6 & 3.5 & 53.1 & 73.8 \\
\hline Yield grade score & 72,969 & 1.78 & 0.65 & 1 & 4 \\
\hline Carcass price $(1,000$ Won $)$ & 6,842 & $5,594.4$ & $1,925.7$ & 421.9 & $12,180.4$ \\
\hline Marbling score & 50,754 & 4.24 & 2.13 & 1 & 9 \\
\hline Meat color score & 25,531 & 4.00 & 1.04 & 2 & 7 \\
\hline Fat color score & 25,531 & 3.04 & 0.33 & 2 & 7 \\
\hline Texture score & 25,531 & 1.49 & 0.50 & 1 & 3 \\
\hline Maturity score & 25,570 & 4.45 & 2.09 & 1 & 9 \\
\hline Quality grade score & 72,969 & 2.93 & 1.17 & 1 & 6 \\
\hline Price/kg (1,000 Won) & 6,842 & 14.7 & 3.7 & 3.3 & 25.8 \\
\hline
\end{tabular}

$\mathrm{SD}$, standard deviation; LM, longissimus muscle. 
Table 3. Distribution (\%) of carcasses stratified by Korean quality and yield grades $(n=72,969)$

\begin{tabular}{lcccccc}
\hline \multirow{2}{*}{ Yield grade } & \multicolumn{6}{c}{ Quality grade (\%) } \\
\cline { 2 - 7 } & $1++$ & $1+$ & 1 & 2 & 3 & $\mathrm{D}^{1}$ \\
\hline $\mathrm{A}$ & 2.4 & 5.6 & 8.6 & 9.9 & 7.7 & - \\
$\mathrm{B}$ & 3.9 & 10.8 & 17.3 & 16.4 & 5.5 & - \\
$\mathrm{C}$ & 1.1 & 2.5 & 3.8 & 3.0 & 1.1 & - \\
$\mathrm{D}^{1}$ & - & - & - & - & - & 0.3 \\
\hline \multicolumn{1}{l}{ Grades of D were primarily assigned due to high maturity, blood } \\
\multicolumn{5}{c}{ splashing and carcass blemishes. }
\end{tabular}

Bonsmara, and Romosinuano ranged from 331 to $366 \mathrm{~kg}$ (Ríos-Utrera et al., 2005; Casas et al., 2010). Even though Hanwoo are considered a lighter breed, their size was found to be similar (average carcass weight $=357.1 \mathrm{~kg}$ ) to that of typical beef breeds. The average backfat thickness and LM area of crossbreeds ranged from 9.5 to $13 \mathrm{~mm}$ and 81.6 to $87 \mathrm{~cm}^{2}$ (Casas et al., 2010), while the means in this study differed slightly, being $11.3 \mathrm{~mm}$ and $81.1 \mathrm{~cm}^{2}$, respectively. The results of this study and previous studies showed slight differences in the locations at which the traits were measured. As shown in Figure 1, the backfat thickness and LM area were measured between the last thoracic vertebrae and the first lumbar. However, in the United States, ribeye area is measured as the surface area on the cut space of the ribeye muscle between the 12th and 13th ribs. Furthermore, fat thickness is measured at $75 \%$ of the length of the longissimus dorsi muscle from the split chine bone as the amount of fat opposite the rib eye at the cut space (http://www.thebeefsite.com). Nevertheless, the results indicated a numerical increase of $85 \mathrm{~kg}$ in carcass weight and $10.6 \mathrm{~cm}^{2}$ in LM area relative to the results $(\mathrm{n}=20,881)$ reported for Hanwoo by Park et al. (2002), which represents a significant improvement in beef production for such a relatively short period.
Both yield and quality grades were converted to numeric scores for this study, and the means of marbling score (4.24) and quality grade (2.93) indicated the third level (grade 1) of quality. Furthermore, the means of the yield index and yield grade (66.78 and 1.78, respectively) indicated second level (B) grades. The USDA and Korean yield grades showed differences in cutability, with the Korean yield grades being $34.2 \%$ for A, $53.9 \%$ for B, and $11.5 \%$ for $\mathrm{C}$, while the USDA yield grades were $15.3 \%$ for grade $1,71.7 \%$ for grade 2 and 3, and $13.0 \%$ for grade 4 and 5 (Moore et al., 2012). The distributions of Korean quality grades were $7.5 \%$ for $1++, 18.9 \%$ for $1+, 29.7 \%$ for $1,29.3 \%$ for 2 , and $14.3 \%$ for 3 . The USDA quality distributions (Moore et al., 2012) were 2.1\% for Prime, $58.9 \%$ for Choice, $32.6 \%$ for Select, $5.1 \%$ for Standard, $0.9 \%$ for Commercial, and $0.3 \%$ for Utility. The proportion of USDA Prime was lower than that of Korean 1++, which are the best grades in terms of quality, but are measured differently. Conversely, the proportion of cattle categorized as USDA Choice was higher than that of cattle categorized as Korean 1+, which are the second levels of quality grade in both countries. Roast beef without spice is widely consumed by Koreans, whereas marinated steaks with spice are popular in the United States. This difference in taste may lead to the quality grades in Korea being more sensitive to flavor and tenderness than the USDA quality grades, while the difference in the proportions of grades may reflect consumer preference and consumption patterns of both countries.

\section{Variance components and heritabilities}

Heritabilities were presented separately for quantity and quality attributes. The quantity traits, which included carcass measurements (fat thickness, muscle area and carcass weight), yield index, yield grade, and CP, are

Table 4. Variance components and heritabilities of the carcass traits

\begin{tabular}{lcccc}
\hline Traits & Additive variance & Residual variance & $\mathrm{h}^{2}$ & \pm SE \\
\hline Quantity attribute & & & & \\
Backfat thickness & 4.947 & 19.711 & 0.20 & 0.018 \\
LM area & 24.913 & 84.334 & 0.23 & 0.020 \\
Carcass weight & 573.401 & 1500.880 & 0.28 & 0.019 \\
Yield index & 2.580 & 9.701 & 0.20 & 0.018 \\
Yield grade & 1.512 & 8.268 & 0.16 & 0.017 \\
Carcass price (1,000 won) & $600,390.000$ & $1,440,310.000$ & 0.29 & 0.024 \\
Quality attribute & & & & 0.021 \\
Marbling score & 1.130 & 2.896 & 0.06 & 0.013 \\
Meat color score & 1.101 & 17.580 & 0.06 & 0.012 \\
Fat color score & 0.692 & 10.676 & 0.14 & 0.016 \\
Texture score & 0.033 & 0.201 & 0.41 & 0.031 \\
Maturity score & 0.551 & 0.801 & 0.26 & 0.016 \\
Quality grade & 4.428 & 12.563 & 0.24 & 0.025 \\
Price/kg (1,000 won) & 38.773 & 125.356 & & \\
\hline
\end{tabular}

SE, standard error; LM, longissimus muscle. 
presented in the first half of Table 4. Our estimated heritability for LM area was $0.23 \pm 0.02$, which lower than the mean heritability estimate of 0.41 from 36 estimates (of the previous studies) reported by Utrera and Van Vleck (2006) and 0.33 from 3 estimates found in Hanwoo (Lee, 2004; Roh et al., 2004; Hwang et al., 2008). The heritability estimate for backfat thickness was $0.20 \pm 0.018$, which is smaller than the values of 0.25 and 0.63 reported by Gregory et al. (1995) and Riley et al. (2002), respectively. Hwang et al. (2008) and Roh et al. (2004) reported 0.44 and 0.42 , respectively in Hanwoo. Utrera and Van Vleck (2006) reported a mean heritability estimate of 0.41 for the adjusted backfat thickness based on 36 estimates. The estimated carcass weight heritability was $0.28 \pm 0.019$ and similar to the results of the previous studies in Hanwoo (Lee, 2004; Roh et al., 2004; Hwang et al., 2008), while those of studies in other breeds (Gregory et al., 1995; Wulf et al., 1996; Riley et al., 2002) ranged from 0.15 to 0.55 . Utrera and Van Vleck (2006) reported a mean heritability of 0.42 for carcass weight adjusted to a constant age. Previous studies based on small datasets primarily consisted of higher heritability values (Brackelsberg et al., 1971; Benyshek, 1981; Davis and Simmen, 2000; Nephawe et al., 2004; Smith et al., 2007; Nogi et al., 2011; Mao et al., 2013). It was assumed that small environmental or residual variation occurred in the limited or controlled experiments. In the present study, the heritabilities of the three measurement traits (carcass weight, backfat thickness, and LM area) were moderate. The records of beef cattle raised on 1,647 farms were collected from packing plants throughout the country, which may have led to greater variation associated with environmental or other unknown effects. However, similar estimates of $0.20,0.24$, and 0.27 for adjusted fat thickness, LM area and hot carcass weight, respectively, were reported by Ríos-Utrera et al. (2005).

Yield index, which is often referred to as the lean index, reflects cutability and is a function of carcass measurements including backfat thickness, LM area, and carcass weight. Our heritability estimates for yield grade and index were lower than previous estimates for yield grade of $0.30 \pm 0.08$, $0.46 \pm 0.18,0.54 \pm 0.19,0.46 \pm 0.17,0.85 \pm 0.14$, and $0.76 \pm 0.26$ reported by Ríos-Utrera et al. (2005), Davis and Simmen (2000), Pariacote et al. (1998), Smith et al. (2007), Wheeler et al. (2001), and Wulf et al. (1996), respectively.

The CP was determined based on both the weight and quality of the carcass. The heritability of $\mathrm{CP}$ was $0.29 \pm 0.24$, which was lower than the value of 0.53 for carcasses (Brackelsberg et al., 1971) and 0.34 for cattle price at auction (McHugh et al., 2011). The genetic effects of a price trait can be considered a composite economic index of economic traits. Accordingly, the prices cited above could have similar properties as composite indices, even at different stages of lifetime.
The genetic parameters associated with the carcass characteristics, quality grade, and price per $\mathrm{kg}$ are presented in the second half of Table 4 . The heritability of marbling score $(0.28 \pm 0.021)$ was similar or lower than the estimates from studies reported by Davis and Simmen (2000), RíosUtrera et al. (2005) and Nephawe et al. (2004) (0.27 \pm 0.17 , $0.40 \pm 0.09,0.46 \pm 0.06$, respectively), in which they agreed in general that marbling had a significant effect on carcass quality and was moderately heritable. The heritability estimates for marbling score in Hanwoo by Lee (2004), Hwang et al. (2008) and Roh et al. (2004) were ranged from 0.45 to 0.54 , which were higher than the estimates in this study and the estimates for other breeds mentioned above.

The heritability estimates for lean color $(0.34)$ reported by Pratt et al. (2013) and meat color (0.19) reported by Dinkel and Busch (1973) were much higher than the estimates in the present study (both 0.06 in Table 4). The heritabilities of redness, yellowness and lightness were 0.33 , 0.28 , and 0.21 , respectively, in a study conducted by Bonfatti et al. (2013), and 0.29, 0.28 and 0.09 reported by Pratt et al. (2013). The carcass Commission Internationale de l'Eclairage color data were obtained using chroma meters, then converted for analysis (Francis and Clydesdale, 1975; Hunter and Harold, 1987). However, the scores of meat and fat color were assigned based on visual observation by graders using visual help kits, which may have caused increased variation and reduced accuracy in the present study.

The heritability of texture score $(0.14 \pm 0.016)$ was lower than 0.29 with a standard error of \pm 0.17 for lean firmness in a study by Dinkel and Busch (1973) and $0.26 \pm 0.08$ for taste panel tenderness in an investigation by Nephawe et al. (2004). The heritability of maturity score was very high in the present study $(0.41 \pm 0.031)$ relative to the estimates reported by Smith et al. (2007; $0.10 \pm 0.10$ and $0.00 \pm 0.08$ for skeletal and lean maturity, respectively). In the present study, age at slaughter was included in the model as a covariate, which may have led to age effects on maturity scores, reduced residual variation, and high heritability.

The heritabilities of carcass quality grade reported by the USDA ranged from 0.25 to 0.29 (Dinkel and Busch, 1973; Davis and Simmen, 2000), which were similar to the results of the present study. Quality grades and price/kg are both related to carcass value, and the heritability of price $/ \mathrm{kg}$ was similar to the quality grade in the present study $(0.24 \mathrm{vs}$ 0.26 in Table 4).

\section{Genetic and phenotypic correlations}

The average standard error (SE) associated with the genetic correlations among 13 traits was 0.079 , ranging from 0.003 to 0.161 , which was smaller than the values reported by Bergen et al. (2006) (0.11, ranging from 0.03 to 0.22 ) and Smith et al. (2007) (0.30, ranging from 0.01 to 
Table 5. Genetic (below diagonal) and phenotypic (above diagonal) correlations of carcass measurements, yield indicators and carcass price

\begin{tabular}{lcccrcc}
\hline Traits & Backfat thickness & LM area & Carcass weight & Yield index & Yield grade & Carcass price \\
\hline Backfat thickness & & $0.08 \pm 0.006$ & $0.31 \pm 0.005$ & $-0.95 \pm 0.001$ & $0.76 \pm 0.002$ & $0.20 \pm 0.008$ \\
LM area & $-0.07 \pm 0.065$ & & $0.62 \pm 0.003$ & $0.13 \pm 0.006$ & $-0.26 \pm 0.005$ & $0.45 \pm 0.007$ \\
Carcass weight & $0.17 \pm 0.056$ & $0.80 \pm 0.026$ & & $-0.35 \pm 0.005$ & $0.09 \pm 0.006$ & $0.60 \pm 0.006$ \\
Yield index & $-0.97 \pm 0.005$ & $0.19 \pm 0.064$ & $-0.18 \pm 0.056$ & & $-0.80 \pm 0.002$ & $-0.18 \pm 0.009$ \\
Yield grade & $0.91 \pm 0.016$ & $-0.43 \pm 0.058$ & $-0.09 \pm 0.063$ & $-0.95 \pm 0.009$ & & $-0.04 \pm 0.008$ \\
Carcass price & $0.01 \pm 0.076$ & $0.61 \pm 0.054$ & $0.57 \pm 0.047$ & $-0.03 \pm 0.080$ & $-0.23 \pm 0.075$ & \\
\hline
\end{tabular}

LM, the longissimus muscle.

Standard errors of genetic correlations ranged from \pm 0.017 to \pm 0.080 ; standard errors of phenotypic correlations ranged from \pm 0.001 to \pm 0.009 .

$0.50)$.

Quantity attribute: Correlations of traits with quantity attributes are given in Table 5. The average SE associated with the genetic correlations was 0.050 , ranging from 0.005 to 0.080. Backfat thickness showed a high genetic and phenotypic relationship with yield grade and yield index, similar to the results reported by Brackelsberg et al. (1971), Ríos-Utrera et al. (2005), Smith et al. (2007) and Wheeler et al. (2001). Fatter carcass was generally associated with higher yield grade (0.91) and lower LM area (-0.07). However, no significant relationship except for yield grade and index was found.

Hwang et al. (2008) found that the genetic correlation between LM area and back fat thickness was -0.24 , which was much higher than $-0.07 \pm 0.065$ in this study. LM area showed significant positive genetic and phenotypic correlations with carcass weight and CP that were higher than the results reported by Brackelsberg et al. (1971) and Ríos-Utrera et al. (2005). The genetic correlation of LM area with carcass weight was 0.80 , which was higher than the results of Hanwoo by Hwang et al. (2008) and Roh et al. (2004) (0.63 and 0.65, respectively). Smith et al. (2007) reported correlations of LM area with body weight at slaughter and hot carcass weight of 0.31 and 0.45 , respectively. LM area showed low positive genetic correlations with yield index and moderate negative correlation with yield grade. This contradicts the high positive genetic correlation (0.95) observed between LM area and cutability reported by Dinkel and Busch (1973), Smith et al. (2007) and Wheeler et al. (2001). These findings suggested that LM area did not have as great an influence on cutability in Korea as in the United States.

Carcass weight had moderate negative genetic $(-0.18)$ and phenotypic $(-0.35)$ correlations with yield index, but showed low genetic (-0.09) and phenotypic (0.09) correlation with yield grade. Ríos-Utrera et al. (2005) reported that the genetic correlation between hot carcass weight and USDA yield grade was 0.42 in steer after adjustment for age. However, carcass weight in the yield index equation was negative.

Since yield grades were assigned according to the yield index, yield grade and index have the same attributes, but different directions of assigned value for favorable carcass (Table 1). Yield grade was positively correlated with backfat thickness (0.91) and negatively correlated with LM area $(-0.43)$, which were very similar to the values of 0.79 and -0.49 , respectively, reported by Smith et al. (2007).

The genetic and phenotypic correlations of CP with LM area and carcass weight were moderately positive, and hence seemed to be positive factors for determining CP. The estimates of genetic correlations between LM area and backfat thickness with $\mathrm{CP}$ (0.61 and 0.01; Table 5) were different from the respective estimates of 0.51 and -0.85 reported by Brackelsberg et al. (1971), which implies that consumers in Korea and the United States react differently to fat thickness.

Quality attribute: Correlations of traits with quality attributes are shown in Table 6 and the average SE associated with the genetic correlations was 0.087, ranging from 0.003 to 0.161 , which was greater than the $\mathrm{SE}$ values

Table 6. Genetic (below diagonal) and phenotypic (above diagonal) correlations of carcass characteristic scores, quality grade and price per $\mathrm{kg}$

\begin{tabular}{lccccccc}
\hline & MS & MC & FC & Texture & Maturity & QG & Price/kg \\
\hline Marbling score (MS) & & $-0.18 \pm 0.010$ & $0.01 \pm 0.010$ & $-0.70 \pm 0.005$ & $0.04 \pm 0.011$ & $-0.95 \pm 0.001$ & $0.67 \pm 0.005$ \\
Meat color (MC) & $-0.42 \pm 0.137$ & & $0.09 \pm 0.010$ & $0.17 \pm 0.010$ & $0.07 \pm 0.010$ & $0.19 \pm 0.010$ & $-0.15 \pm 0.018$ \\
Fat color (FC) & $-0.40 \pm 0.087$ & $0.60 \pm 0.161$ & & $0.06 \pm 0.010$ & $0.10 \pm 0.011$ & $0.03 \pm 0.010$ & $-0.04 \pm 0.017$ \\
Texture & $-0.96 \pm 0.035$ & $0.54 \pm 0.142$ & $0.57 \pm 0.112$ & & $0.09 \pm 0.010$ & $0.76 \pm 0.004$ & $-0.57 \pm 0.012$ \\
Maturity & $-0.08 \pm 0.073$ & $0.47 \pm 0.134$ & $0.66 \pm 0.081$ & $0.25 \pm 0.087$ & & $0.05 \pm 0.010$ & $-0.06 \pm 0.020$ \\
Quality grade (QG) & $-0.99 \pm 0.003$ & $0.48 \pm 0.143$ & $0.47 \pm 0.093$ & $0.98 \pm 0.015$ & $0.18 \pm 0.016$ & & $-0.70 \pm 0.005$ \\
Price/kg & $0.76 \pm 0.038$ & $-0.41 \pm 0.145$ & $-0.37 \pm 0.157$ & $-0.79 \pm 0.050$ & $-0.42 \pm 0.084$ & $-0.80 \pm 0.034$ & \\
\hline
\end{tabular}

Standard errors of genetic correlations ranged from \pm 0.003 to \pm 0.161 , and standard errors of phenotypic correlations ranged from \pm 0.001 to \pm 0.020 . 
reported for the quantity attributes. Similarly, the average absolute value $(0.552)$ of the genetic correlations was greater than the value of 0.414 reported for the quantity attributes. Moreover, traits with quality attributes appeared to be more closely related to each other than quantity attributes. Disagreements between negative and positive correlations between the present study and previous studies were primarily due to the different directions of assigned scores for each trait.

Marbling score was most highly correlated with texture score and quality grade $(-0.96$ and -0.99$)$, while it was moderately correlated with scores of meat and fat color $(-0.42$ and -0.40$)$, and slightly correlated with maturity $(-0.08)$. The genetic correlation of marbling with quality grade was similar to the value of 0.90 reported by Dinkel and Busch (1973).

Meat and fat color were genetically correlated to each other (0.60), and moderately correlated with texture, maturity and quality grade (0.47 to 0.66 ). Dinkel and Busch (1973) reported that lean color had genetic correlations of -0.19 and 0.40 with lean firmness and carcass grade, respectively. The relationships of meat (0.48) and fat (0.47) color with quality grade observed in the present study were similar to their results; however, the genetic correlation $(-0.19)$ of lean color with lean firmness was lower than our estimate of 0.54 for the correlation of meat color with texture. Texture was moderately correlated with maturity $(0.25)$, but highly correlated with quality grade $(0.98)$. Conversely, Dinkel and Busch (1973) reported low genetic correlation (0.11) of lean firmness with carcass grade (USDA quality grade).

The phenotypic correlations of maturity with other carcass characteristic scores observed in the present study ranged from 0.04 to 0.10 (Table 6). Similarly, Schreurs et al. (2008) reported that the characteristics did not differ significantly according to the degree of maturity in loin, round and chuck meat upon meta-analysis. However, the genetic correlations of maturity with meat color, fat color and texture were $0.47,0.66$, and 0.25 , respectively. The genetic correlations of maturity with marbling and quality grade were low ( -0.08 and 0.18 , respectively), but Smith et al. (2007) reported values of $-0.45 \pm 0.47$ and $-0.44 \pm 0.45$ for correlations with both traits. In general, there appeared to be low phenotypic and moderate genetic correlation of maturity with other carcass quality traits.

Our estimates of genetic correlations of quality grade with the carcass characteristic scores were generally moderate or high, ranging from -0.99 to 0.98 , except for maturity. APGS assigned a grade of D (for both quality and yield grade) for all carcasses with defects, and maturity was the last characteristic considered to determine the final quality grade from the provisional grade. These findings may reduce the relationship of quality grade with maturity. Similarly, Moore et al. (2011) reported that the USDA quality grade was determined by assessing the degree of marbling and firmness relative to the maturity and fat color of the carcass.

Price/kg showed genetic correlations with fat color, meat color, maturity, marbling, and texture that occurred in the order of absolute value size; accordingly, the influence of each trait on carcass value was likely in the same order. As expected, price per $\mathrm{kg}$ was sensitive to quality. The genetic correlations of price $/ \mathrm{kg}$ also applied to quality grade, and hence marbling and texture were important factors influencing quality grade. The genetic correlation of marbling score with carcass value was -0.85 (Dinkel and Busch, 1973), while it was 0.76 with price/kg in the present study.

Quantity and quality attributes: The relationships of the traits with quality and quantity attributes (Table 7) were generally expected to be weaker than the relationships of the traits within the same attributes (Tables 5 and 6). No significantly high genetic relationship between measurements and scores of carcass characteristics were found except for price traits, and the genetic correlations ranged from -0.27 to 0.21 . The average SE associated with the genetic correlations was 0.086 , ranging from 0.044 to 0.182 , which was similar to that in Table 6 .

Backfat thickness and LM area showed no significant genetic correlations with carcass quality traits. Hwang et al. (2008) reported that the genetic correlations between back fat thickness and marbling score was 0.04, which was similar to $0.07 \pm 0.061$ (Table 7). Also the genetic correlation of LM area and marbling score were $0.15 \pm 0.056$, which was similar to the results of Hwang et al. (2008) and Lee (2004).

The genetic correlation of carcass weight and marbling score in Hanwoo showed variation. The estimate in Table 7 was $0.21 \pm 0.051$ whereas Hwang et al. (2008) and Lee (2004) reported 0.06 and 0.30 , respectively. Carcass weight showed genetic correlations ranging from -0.27 to 0.21 with scores of marbling, meat color, texture, maturity, and quality grade. Similarly, Bonfatti et al. (2013) reported that live daily gain was correlated with color traits, drip loss, $\mathrm{pH}$ and shear force of carcass (with values of 0.11 to 0.54 ), which was correlated with carcass daily gain $(0.75)$ based on the ratio of carcass weight to age at slaughter. Both results indicated that body weight traits including carcass weight and carcass daily gain are genetically related to carcass quality to some extent. However, yield index and grade referring to leanness were not as closely related genetically to carcass characteristic scores as carcass weight.

The genetic correlations of price $/ \mathrm{kg}$ with LM area and carcass weight were found to be high and similar to each other $(0.57$ and 0.64$)$, which was not surprising given the 
Table 7. Genetic and phenotypic correlations between carcass traits

\begin{tabular}{|c|c|c|c|c|c|c|}
\hline & $\mathrm{BF}$ & LM area & CW & YI & YG & $\mathrm{CP}$ \\
\hline \multicolumn{7}{|c|}{ Genetic correlation } \\
\hline Marbling & $0.07 \pm 0.061$ & $0.15 \pm 0.056$ & $0.21 \pm 0.051$ & $-0.07 \pm 0.061$ & $0.02 \pm 0.064$ & $0.64 \pm 0.047$ \\
\hline Meat color & $-0.15 \pm 0.155$ & $-0.11 \pm 0.143$ & $-0.21 \pm 0.134$ & $0.17 \pm 0.153$ & $-0.05 \pm 0.161$ & $-0.20 \pm 0.154$ \\
\hline Fat color & $0.10 \pm 0.099$ & $-0.09 \pm 0.091$ & $-0.03 \pm 0.083$ & $-0.10 \pm 0.097$ & $0.14 \pm 0.101$ & $-0.09 \pm 0.182$ \\
\hline Texture & $-0.05 \pm 0.092$ & $-0.20 \pm 0.084$ & $-0.22 \pm 0.078$ & $0.04 \pm 0.091$ & $0.02 \pm 0.087$ & $-0.73 \pm 0.058$ \\
\hline Maturity & $0.04 \pm 0.082$ & $-0.13 \pm 0.077$ & $-0.27 \pm 0.069$ & $0.01 \pm 0.082$ & $0.09 \pm 0.086$ & $-0.01 \pm 0.085$ \\
\hline Quality grade & $-0.05 \pm 0.064$ & $-0.18 \pm 0.058$ & $-0.23 \pm 0.052$ & $0.05 \pm 0.064$ & $0.01 \pm 0.066$ & $-0.23 \pm 0.044$ \\
\hline Price/kg & $-0.06 \pm 0.077$ & $0.57 \pm 0.055$ & $0.64 \pm 0.046$ & $0.06 \pm 0.076$ & $-0.25 \pm 0.075$ & $0.91 \pm 0.069$ \\
\hline \multicolumn{7}{|c|}{ Phenotypic correlation } \\
\hline Marbling & $0.15 \pm 0.006$ & $0.20 \pm 0.006$ & $0.19 \pm 0.006$ & $-0.11 \pm 0.006$ & $0.05 \pm 0.006$ & $0.67 \pm 0.005$ \\
\hline Meat color & $-0.10 \pm 0.010$ & $0.00 \pm 0.010$ & $-0.05 \pm 0.010$ & $0.10 \pm 0.010$ & $-0.09 \pm 0.010$ & $-0.21 \pm 0.018$ \\
\hline Fat color & $0.03 \pm 0.010$ & $-0.06 \pm 0.010$ & $-0.04 \pm 0.010$ & $-0.03 \pm 0.010$ & $0.06 \pm 0.010$ & $-0.04 \pm 0.017$ \\
\hline Texture & $-0.11 \pm 0.008$ & $-0.17 \pm 0.008$ & $-0.17 \pm 0.008$ & $0.08 \pm 0.008$ & $-0.02 \pm 0.008$ & $-0.59 \pm 0.013$ \\
\hline Maturity & $0.03 \pm 0.010$ & $-0.01 \pm 0.010$ & $-0.08 \pm 0.010$ & $-0.01 \pm 0.010$ & $0.02 \pm 0.010$ & $-0.13 \pm 0.021$ \\
\hline Quality grade & $-0.14 \pm 0.006$ & $-0.20 \pm 0.005$ & $-0.20 \pm 0.005$ & $0.11 \pm 0.006$ & $-0.05 \pm 0.008$ & $-0.73 \pm 0.005$ \\
\hline Price/kg & $0.14 \pm 0.008$ & $0.47 \pm 0.006$ & $0.63 \pm 0.005$ & $-0.14 \pm 0.008$ & $-0.05 \pm 0.008$ & $0.88 \pm 0.002$ \\
\hline
\end{tabular}

$\mathrm{BF}$, backfat thickness; LM, longissimus muscle; CW, carcass weight; YI, yield index; YG, yield grade; and CP, carcass price.

Standard errors of genetic correlations ranged from \pm 0.044 to \pm 0.182 , and standard errors of phenotypic correlations ranged from \pm 0.002 to \pm 0.021 .

high genetic correlation of LM area and carcass weight (0.80 in Table 5). The genetic correlation of price/ $\mathrm{kg}$ with yield grade (favorable to low score) was -0.25 . As expected, greater size and leanness increased the carcass value.

The genetic correlations of $\mathrm{CP}$ with scores of marbling, texture, meat and fat color were $0.64,-0.73,-0.20$, and -0.09 , respectively. The genetic correlations of price $/ \mathrm{kg}$ with marbling score, texture, meat and fat color were 0.76 , $-0.79,-0.41$, and -0.37 , respectively (Table 6 ). These results demonstrated that $\mathrm{CP}$ and price $/ \mathrm{kg}$ showed the same trends in relationships with quality attributes, and that price/kg was more closely related to these attributes than CP. These findings further suggest that marbling and texture are the most important carcass characteristic scores to consider when maximizing income.

The genetic correlations of price $/ \mathrm{kg}$ with $\mathrm{LM}$ area, carcass weight and backfat thickness were $0.57,0.64$, and -0.06 , respectively, while the genetic correlations of $\mathrm{CP}$ with LM area, carcass weight and backfat thickness were $0.61,0.57$, and 0.01 , respectively (Table 5 ). These findings again showed that $\mathrm{CP}$ and price $/ \mathrm{kg}$ showed the same trends as measurement traits, and that price/kg was only adjusted for carcass weight based on CP. Unlike the traits with quality attributes, no relationship between the sizes of the genetic correlation estimates with price/kg and $\mathrm{CP}$ was found. However, LM area and carcass weight were genetically related to both price $/ \mathrm{kg}$ and $\mathrm{CP}$.

\section{Nationwide breeding scheme}

Most studies conducted to estimate genetic parameters for carcass traits have used data from a limited number of producers or experimental stations. Further, reducing variations caused by environmental factors or other sources in those farms has resulted in higher estimates of heritability (Nephawe et al., 2004; Ríos-Utrera et al., 2005; Bergen et al., 2006; Nogi et al., 2011). Conversely, field records in the present study were collected by APGS and from herd recording centers (Hanwoo Saupdan) throughout Korea, which are similar to dairy record processing centers in the United States. Carcass records were collected by APGS using nationwide animal identification data tagged by the Hanwoo Traceability System and pedigree information from the KAIA. The data provided in Table 2 included cows, bulls and steers. Differences in animal weight according to sex and age distribution of the animals are presented in Figure 2. Most bulls and steers were slaughtered within 36 months (average $=25.8$ and 30.5 months, respectively), whereas cows were primarily used for reproduction and therefore commonly raised for over 80 months (average $=48.7$ months). All of the above records were used to evaluate bulls for AI. The procedures for bull selection are similar to the national procedures, including the progeny test of dairy bulls, operated by the National Agricultural Cooperative Federation (NACF).

Even though evaluation of models was outside the scope of the present study, careful consideration was given to identification of proper models for analysis of field data. Koots et al. (1994) reviewed many studies of beef cattle and showed that there was no difference between heritability estimates when an animal model or other models were used or between estimates that did or did not include maternal effects. More than $70 \%$ of farmers raised less than 20 head of cattle, and the average herd size was 23.1 head (Statistics Korea, 2013). The herd recording centers operated by the 
NACF provide technical services, including mating and feeding plans with the same schemes, to member farms under its control. In addition, the NACF collects animal information regarding LM area and body weights of live cattle. Therefore, the recording centers $(n=8)$ were considered the primary fixed effect to account for environmental effects instead of farms. Lee et al. (2000) reported that genetic evaluation models of Hanwoo with changing fixed effect groups did not lead to significant differences in the ranking of sires for slaughter weight. They suggested that this indicated that carcass traits were not influenced by environments as much as growth traits. No pre-adjustments, partitions or restrictions for age on carcass traits, carcass weight and fat thickness (Lee et al., 2000; Bergen et al., 2006; McHugh et al., 2011) were adopted for the analysis conducted in the present study; rather, we attempted to adjust the models to account for such effects. Setting constants for factors or traits with field data results in exclusion or adjustment of records because animals are slaughtered at various ages or sizes. Age at slaughter determined by farmers influences almost all carcass traits. Lee et al. (2000) suggested including slaughter age in the model as a covariate for estimation of genetic parameters of Hanwoo carcasses. Manipulation of measurement traits for analysis of characteristic traits may lead farmers to ignore their potential to aid in improving carcass quality through selection. Measurement traits such as carcass weight, LM area and fat thickness may be related to carcass characteristic traits such as marbling and texture. Simultaneous analysis that considers genetic relationships of both measurement and characteristic traits with a multitrait model may help address the issue, but no previous studies appraising genetic parameter estimation or genetic evaluation were found in a literature search.
Changes in the average breeding values of carcass traits for selection of cows carried out mainly in herd recording centers may reflect the selection response. The genetic trends in carcass weight, LM area, marbling and texture for animals are shown in Figure 3. Smith et al. (2007) reported that tenderness traits were emphasized by the current beef cattle industry, while marbling and texture of carcass are the major traits affecting quality grade and price of carcass. The results of the present study showed that carcass weight and LM area were important to yield grade and price, and that marbling and texture were important carcass characteristics influencing quality grade and price. Further, those measurements and traits were genetically and closely related to each other. Even though backfat thickness affected yield grade, it did not influence quality grade and price as much as expected. As shown in Figure 3, the increase (over $8 \mathrm{~kg}$ ) in breeding value of carcass weight from birth year 2000 through 2009 partly explained the increase of carcass weight in the phenotypic results reported by Park et al. (2002). The mean breeding value of marbling score decreased by -0.2 during the same period. These findings indicate that emphasis was placed on growth, while no attention was given to selection of quality characteristics. The drastic change in genetic trends observed in 2009 and 2010 reflects shifts in emphasis from growth to quality.

\section{IMPLICATIONS}

The beef cattle breeding scheme in Korea was designed for data collection, genetic evaluation and selection at the national scale. Even though the heritability estimates in the present study were generally lower than those reported in the literature, genetic progress was found in most traits to some extent. The magnitude of genetic parameters for

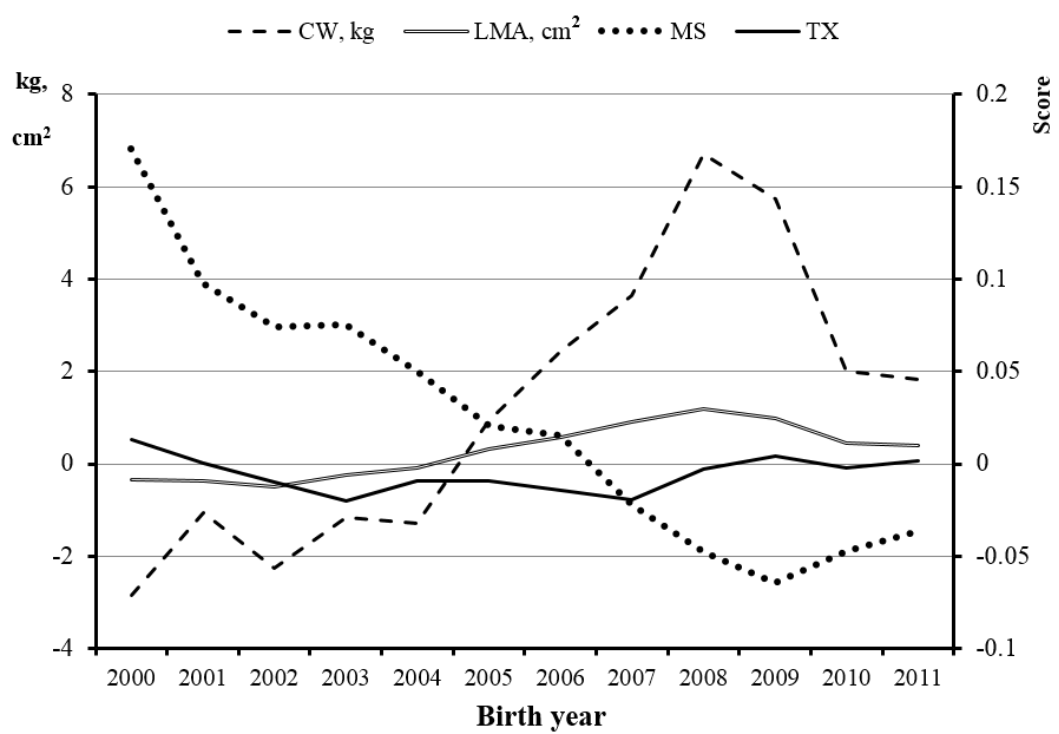

Figure 3. Breeding values according to birth year. CW, carcass weight; LMA, longissimus muscle area; MS, marbling score; TX, texture score. 
carcass and price traits implied that genetic improvements in productivity and carcass quality could be obtained under a large scale breeding scheme. The selection of AI sires for the Hanwoo population of three million head by the National Institute of Animal Science was the primary tool used to accomplish this, while the work conducted by 58 herd recording centers around Korea facilitated this selection by providing methods for improving the genetic capacity of cows on behalf of the farms. However, further research is needed to improve the selection scheme for both bulls and cows.

\section{CONFLICT OF INTEREST}

We certify that there is no conflict of interest with any financial organization regarding the material discussed in the manuscript.

\section{ACKNOWLEDGMENTS}

This study was financially supported by the 2013 Intramural Research Fund of Chungnam National University and involved in the Hanwoo Cow Performance Test Project operated by the National Institute of Animal Science in Korea. Data in this study were provided by the Korea Animal Improvement Association and Korea Institute of Animal Quality Evaluation.

\section{REFERENCES}

Benyshek, L. L. 1981. Heritabilities for growth and carcass traits estimated from data on Herefords under commercial conditions. J. Anim. Sci. 53:49-56.

Bergen, R., S. P. Miller, J. W. Wilton, and I. B. Mandell. 2006. Genetic correlations between live yearling bull and steer carcass traits adjusted to different slaughter end points. 2. Carcass fat partitioning. J. Anim. Sci. 84:558-566.

BIF. 2010. Guidelines for Uniform Beef Improvement Programs. 11th ed. Beef Improv. Fed., Univ. of Georgia, Athens, GA, USA.

Bonfatti, V., A. Albera, and P. Carnier. 2013. Genetic associations between daily BW gain and live fleshiness of station-tested young bulls and carcass and meat quality traits of commercial intact males in Piemontese cattle. J. Anim. Sci. 91:2057-2066.

Brackelsberg, P. O., E. A. Kline, R. L. William, and L. N. Hazel. 1971. Genetic parameters for selected beef-carcass traits. J. Anim. Sci. 33:13-17.

Casas, E., R. M. Thallman, L. A. Kuehn, and L. V. Cundiff. 2010. Postweaning growth and carcass traits in crossbred cattle from Hereford, Angus, Brangus, Beefmaster, Bonsmara, and Romosinuano maternal grandsires. J. Anim. Sci. 88:102-108.

Choy, Y. H., H. B. Yoon, S. B. Choi, and H. W. Jung. 2005. Genetic analysis of carcass traits in Hanwoo with different slaughter end-points. J. Anim. Sci. Technol. (Kor.). 47:703-710 (In Korean).
Davis, M. E. and R. C. M. Simmen. 2000. Genetic parameter estimates for serum insulin-like growth factor-I concentration and carcass traits in Angus beef cattle. J. Anim. Sci. 78:23052313.

Dinkel, C. A. and D. A. Busch. 1973. Genetic parameters among production, carcass composition and carcass quality traits of beef cattle. J. Anim. Sci. 36:832-846.

Francis, F. J. and F. M. Clydesdale. 1975. The measurement of meat color. In: Food Colorimetry: Theory and Application. The AVI Publishing Company, Westport, CT, USA. pp. 73-111.

Gregory, K. E., L. V. Cundiff, and R. M. Koch. 1995. Genetic and phenotypic (co)variances for growth and carcass traits of purebred and composite populations of beef cattle. J. Anim. Sci. 73:1920-1926.

Hocquette, J. F., R. I. Richardson, S. Prache, F. Medale, G. Duffy, and N. D. Scollan. 2005. The future trends for research on quality and safety of animal products. Ital. J. Anim. Sci. 4:4972.

Hunter, R. S. and R. W. Harold. 1987. Uniform color scales: Munsell-based scales. In: The Measurement of Appearance. 2nd edn. Hunter Associates Laboratory, Reston, VA, USA. pp. 135-148.

Hwang, J. M., S. Kim, Y. H. Choy, H. B. Yoon, and C. J. Park. 2008. Genetic parameter estimation of carcass traits of Hanwoo steers. J. Anim. Sci. Technol. (Kor.) 50:613-620.

Koots, K. R., J. P. Gibson, C. Smith, and J. W. Wilton. 1994. Analyses of published genetic parameter estimates for beef production traits. 1. Heritability. Anim. Breed. Abstr. 62:309337.

Koh, D., J. Lee, S. Won, C. Lee, and J. Kim. 2014. Genetic relationships of carcass traits with retail cut productivity of Hanwoo cattle. Asian Australas. J. Anim. Sci. 27:1387-1393.

Korea Institute for Animal Product Quality Evaluation (KIAPQE). 2012. The report of livestock products marketing in Korea. Anyang, Korea.

Lee, D. H. 2004. Methods for genetic parameter estimations of carcass weight, longissimus muscle area and marbling score in Korean cattle. J. Anim. Sci. Technol. (Kor.) 46:509-516.

Lee, J. W., S. B. Choi, J. S. Kim, J. F. Keown, and L. D. Van Vlec. 2000. Parameter estimates for genetic effects on carcass traits of Korean native cattle. J. Anim. Sci. 78:1181-1190.

Lee, S. K., Panjono, S. M. Kang, T. S. Kim, and Y. S. Park. 2008. The effects of dietary sulfur and vitamin E supplementation on the quality of beef from the longissimus muscle of Hanwoo bulls. Asian Australas. J. Anim. Sci. 21:1059-1066.

Liang, K., B. Qaqish, and S. L. Zeger. 1992. Multivariate regression analyses for categorical data. J. R. Statist. Soc. B 54: 3-40.

Mao, F., L. Chen, M. Vinsky, E. Okine, Z. Wang, J. Basarab, D. H. Crews, Jr. and C. Li. 2013. Phenotypic and genetic relationships of feed efficiency with growth performance, ultrasound, and carcass merit traits in Angus and Charolais steers. J. Anim. Sci. 91:2067-2076.

McHugh, N., R. D. Evans, P. R. Amer, A. G. Fahey, and D. P. Berry. 2011. Genetic parameters for cattle price and body weight from routinely collected data at livestock auctions and commercial farms. J. Anim. Sci. 89:29-39.

Meyer, K. 2013. WOMBAT: A program for mixed model analyses 
by restricted maximum likelihood. http://didgeridoo.une. edu.au/km/homepage.php Accessed August 10, 2015.

Moore, M. C., G. D. Gray, D. S. Hale, C. R. Kerth, D. B. Griffin, J. W. Savell, C. R. Raines, K. E. Belk, D. R. Woerner, J. D. Tatum, J. L. Igo, D. L. VanOverbeke, G. G. Mafi, T. E. Lawrence, R. J. Delmore, Jr, L. M. Christensen, S. D. Shackelford, D. A. King, T. L. Wheeler, L. R. Meadows, and M. E. O'Connor. 2012. National beef quality audit-2011: Inplant survey of targeted carcass characteristics related to quality, quantity, value, and marketing of fed steers and heifers. J. Anim. Sci. 90:5143-5151.

Nephawe, K. A., L. V. Cundiff, M. E. Dikeman, J. D. Crouse, and L. D. Van Vleck. 2004. Genetic relationships between sexspecific traits in beef cattle: Mature weight, weight adjusted for body condition score, height and body condition score of cows, and carcass traits of their steer relatives. J. Anim. Sci. 82:647-653.

Nogi, T., T. Honda, F. Mukai, T. Okagaki, and K. Oyama. 2011. Heritabilities and genetic correlations of fatty acid compositions in longissimus muscle lipid with carcass traits in Japanese Black cattle. J. Anim. Sci. 89:615-621.

Pariacote, F., L. D. Van Vleck, and R. E. Hunsley. 1998. Genetic and phenotypic parameters for carcass traits of American Shorthorn beef cattle. J. Anim. Sci. 76:2584-2588

Park, B., T. Choi, S. Kim, and S.-H. Oh. 2013. National genetic evaluation (system) of Hanwoo (Korean native cattle). Asian Australas. J. Anim. Sci. 26:151-156.

Park, G. B., S. S. Moon, Y. D. Ko, J. K. Ha, J. G. Lee, H. H. Chang, and S. T. Joo. 2002. Influence of slaughter weight and sex on yield and quality grades of Hanwoo (Korean native cattle) carcasses. J. Anim. Sci. 80:129-136.

Pratt, P. J., D. W. Moser, L. D. Thompson, S. P. Jackson, B. J. Johnson, A. J. Garmyn, and M. F. Miller. 2013. The heritabilities, phenotypic correlations, and genetic correlations of lean color and palatability measures from longissimus muscle in beef cattle. J. Anim. Sci. 91:2931-2937.
Riley, D. G., C. C. Chase, Jr, A. C. Hammond, R. L. West, D. D. Johnson, T. A. Olson, and S. W. Coleman. 2002. Estimated genetic parameters for carcass traits of Brahman cattle. J. Anim. Sci. 80:955-962.

Ríos-Utrera, A., L. V. Cundiff, K. E. Gregory, R. M. Koch, M. E. Dikeman, M. Koohmaraie, and L. D. Van Vleck. 2005. Genetic analysis of carcass traits of steers adjusted to age, weight, or fat thickness slaughter endpoints. J. Anim. Sci. 83:764-776.

Roh, S. H., B. W. Kim, H. S. Kim, H. S. Min, H. B. Yoon, D. H. Lee, J. T. Jeon, and J. G. Lee. 2004. Comparison between REML and Bayesian via gibbs sampling algorithm with a mixed animal model to estimate genetic parameters for carcass traits in Hanwoo (Korean native cattle). J. Anim. Sci. Technol. (Kor.) 46:719-728.

Roh, S. H., C. Y. Kim, Y. S. Won, C. J. Park, S. S. Lee, and J. G. Lee. 2010. Studies on genetic parameter estimation and sire selection to ultrasound measurement traits of Hanwoo. J. Anim. Sci. Technol. (Kor.) 52:1-8.

Smith, T., J. D. Domingue, J. C. Paschal, D. E. Franke, T. D. Bidner, and G. Whipple. 2007. Genetic parameters for growth and carcass traits of Brahman steers. J. Anim. Sci. 85:13771384.

Schreurs, N. M., F. Garcia, C. Jurie, J. Agabriel, D. Micol, D. Bauchart, A. Listrat, and B. Picard. 2008. Meta-analysis of the effect of animal maturity on muscle characteristics in different muscles, breeds, and sexes of cattle. J. Anim. Sci. 86:28722887.

Utrera, A. R. and L. D. Van Vleck. 2006. Heritability estimates for carcass traits of cattle: A review. Genet. Mol. Res. 3:380-394.

Wheeler, T. L., L. V. Cundiff, S. D. Shackelford, and M. Koohmaraie. 2001. Characterization of biological types of cattle (Cycle V): Carcass traits and longissimus palatability. J. Anim. Sci. 79:1209-1222.

Wulf, D. M., J. D. Tatum, R. D. Green, J. B. Morgan, B. L. Golden, and G. C. Smith. 1996. Genetic influences on beef longissimus palatability in charolais- and limousin-sired steers and heifers. J. Anim. Sci. 74:2394-2405. 